\title{
Domestic Wastewater Characterization and Potential for Treatment Using Close-to-Nature Methods
}

\author{
Melvin-Guy Adonadaga ${ }^{1 *}$ Jabab Enoch $^{1} \quad$ Afedo Selorm Kwame ${ }^{2}$ \\ 1. Department of Environmental Science, University for Development Studies, P.O Box 24, Navrongo, Ghana \\ 2. Department of Earth Science, University for Development Studies, P.O Box 24, Navrongo, Ghana
}

\begin{abstract}
Many countries in the developing world face the enormous challenge of effectively handling wastewater generated in urban centres mainly because population growth and urbanization have outpaced provision of sanitation infrastructure. The discharge of untreated wastewater poses risks to human health since it contains excreta-related pathogens as well as other chemical contaminants. The focus of this research was to characterize wastewater generated from educational institutions in Ghana in order to recommend a suitable treatment method. Wastewater samples were collected over a three-month period and tested for physicochemical parameters of relevance to environmental pollution. The bucket and stopwatch method was used to determine the flow rates of the wastewater generated at the various institutions while all other parameters were determined using standard methods. The levels of most of the parameters were generally within the recommended guideline values set by the WHO and the EPA of Ghana. However, chloride, phosphorus and hardness recorded values of $793 \mathrm{mg} / 1,79 \mathrm{mg} / 1$ and $18,500 \mathrm{mg} / 1$, far exceeding their guideline values of $250 \mathrm{mg} / 1,2 \mathrm{mg} / 1$ and $500 \mathrm{mg} / 1$ respectively set by the EPA of Ghana. It is recommended that some pretreatment should be carried out before discharge of the wastewater. Additionally, constructed wetlands are suggested as a suitable method of decentralized treatment considering the strength and flow rate of the wastewater.
\end{abstract}

Keywords: Environmental pollution, Domestic wastewater characterization

DOI: $10.7176 / \mathrm{JEES} / 9-3-05$

Publication date:March $31^{\text {st }} 2019$

\section{Introduction}

The term wastewater is primarily is used to refer to any water that has been used for its intended purpose and thus contains materials added to it during its use. Main activities that result in wastewater generation can be broadly classified as domestic, municipal or industrial. Other sources of wastewater include streets and parking lots during a rainstorm and agricultural run-off. Irrespective of the wastewater source, it usually contains contaminants such as suspended solids, biodegradable matter, dissolved organic compounds, inorganic solids, nutrients, metals, and pathogenic microorganisms (Mara et al, 2004). The suspended solids in wastewater are primarily organic and inorganic particles (Michael et al., 2011).

In most developing countries, wastewater is discharged directly into the environment without adequate treatment, with consequent detrimental impacts on human health, economic productivity, quality of ambient freshwater resources, and ecosystems in general (WWAP, 2017). Globally, diarrhea remains one of the leading causes of death in both adults and children (Walker et al., 2013). According to WHO/UNICEF (2012), 70\% of the population of sub-Saharan Africa remains without access to basic sanitation. Although the risk factors for diarrhea diseases are multi-faceted, an estimated $94 \%$ of cases are attributed to environmental factors such as unsafe drinking water and poor sanitation and hygiene. For example, about 502,000 deaths were associated with inadequate water in the year 2012 while 280,000 deaths associated with inadequate sanitation in the same year from a total of 1.5 million diarrhoea related deaths (Pruss-Ustun et al., 2006). In addition, food hygiene interventions, especially for food that can be eaten uncooked (e.g. salads) remain a challenge especially in low and middle-income countries (LMICs) where access to sanitation and general hygiene are poor. These interventions are further complicated in countries where water is scarce, and wastewater is used for agricultural production (Rousseau \& Sharma 2011). An estimated 20 million hectares worldwide are irrigated with wastewater, more of it with untreated than treated wastewater (Jiménez and Asano, 2008). The use of wastewater in agriculture has been associated with diarrheal disease and helminth infections in both farmers and consumers.

The overall management objectives of wastewater treatment are associated with the removal of pollutants and the protection and preservation of our natural water resources. Most modern wastewater treatment facilities have been developed but very few of such facilities are available and functioning in developing countries. As such, many countries in the developing world face the enormous challenge of effectively handling large quantities of wastewater generated in urban centres due to rapid population growth (Nikiema et al., 2013; Awuah et al., 2014). Attempts to address this problem have mostly proven futile due to a plethora of reasons including lack of adequate knowledge on the nature of the wastewater generated, financial constrains as well as the requisite skilled labour to manage the treatment plants (Graham and Polizzotto, 2013; Awuah et al., 2014). To properly handle wastewater, its characteristics and volume need to be determined in order that a suitable and appropriate treatment method can 
be chosen.

In Ghana, high population growth coupled with rapid urbanization have outpaced sanitation infrastructure provision, leaving especially the urban poor who constitute 44 per cent of the total population virtually without sanitation facilities (Keraita, 2002). The lack of sanitary facilities and waste management systems results in the continuous disposal of untreated wastewater leading to the general pollution of the environment and water resources in particular (Amuzu, 1997; Boadi and Kuitunen, 2002). As such, the use of wastewater for vegetables irrigation is becoming very common in most of the cities in Ghana (Amoah et al., 2016). The use of untreated wastewater, or polluted water in general, poses risks to human health since it may contain excreta-related pathogens such as viruses, bacteria, protozoan and multicellular parasites, skin irritants and toxic chemicals like heavy metals, pesticides and pesticide residues (Bos et al., 2012). Wastewater treatment is important in order to protect public health and also ensure that receiving waters to do suffer oxygen depletion as a result of eutrophication. According to the 2010 Population and Housing Census (GSS, 2014), wastewater generated in the Kassena-Nankana East Municipality is not given any kind of treatment due to the absence of a treatment facility. This has the potential to contaminate surface waters, upper soils and ground water (Norah et al., 2015), with subsequent environmental and health implications. The aim of the research was to characterize wastewater generated within the municipality as a first step towards identifying a suitable treatment method. The specific objectives of our study were: (1) to determine the flow rate and quantity of wastewater generated, (2) to characterize the wastewater based on its composition and quality, and (3) to propose a suitable wastewater treatment method. The outcome of this study should provide useful information with regards wastewater management and also in the broader context of environmental protection.

\section{Methodology}

\subsection{Study Area}

The study was conducted in the Kassena-Nankana East Municipality located in the Upper East Region of Ghana. The municipality lies approximately between latitude $11^{\circ} 10^{\prime}$ and $10^{\circ} 3^{\prime}$ North and longitude $10^{\circ} 1^{\prime}$ West (GSS, 2014).

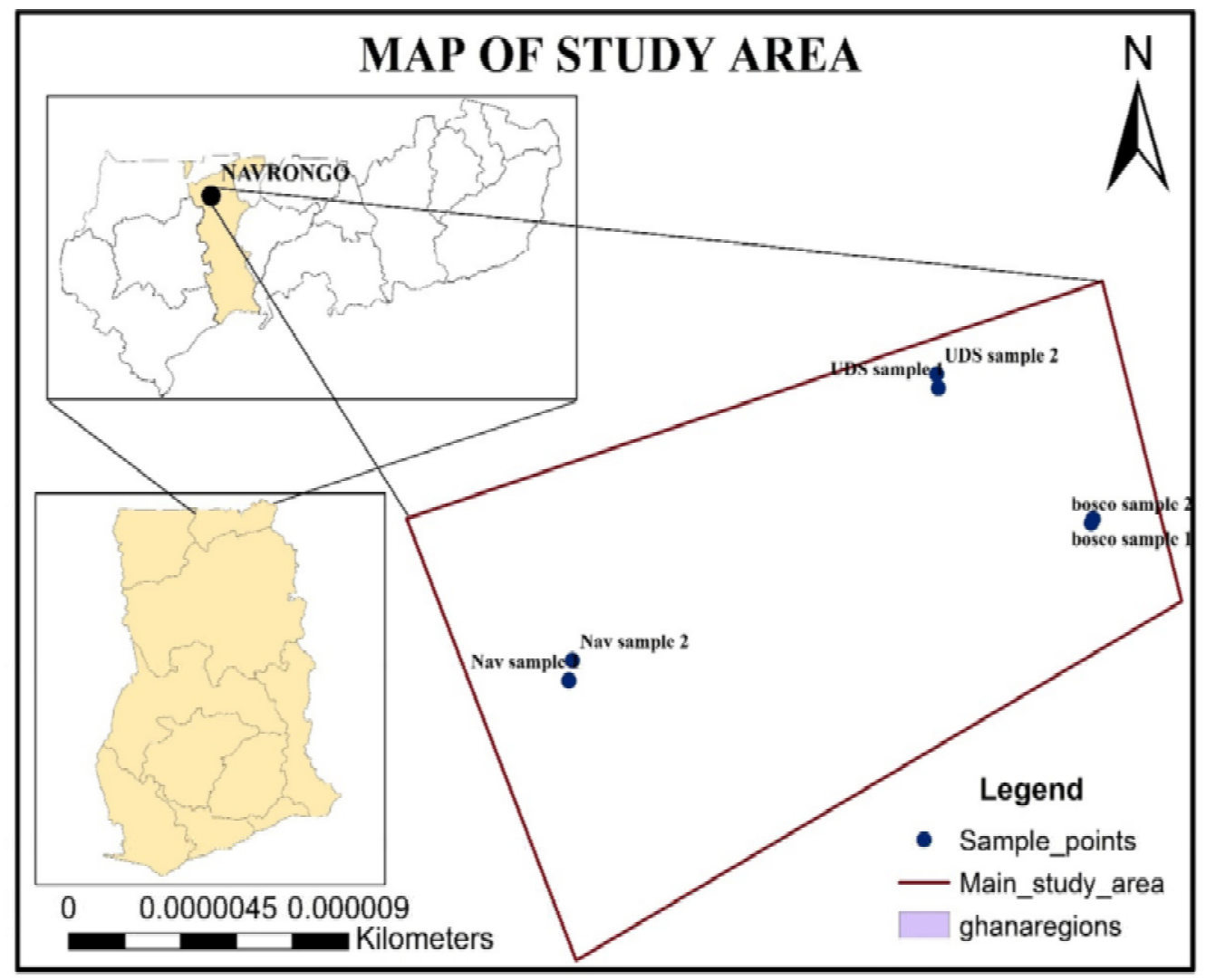

\subsection{Survey}

A survey was done to identify the institutions to be involved in the research and also the points from which the wastewater samples will be collected. Based on the survey, three institutions: University for Development Studies 
(UDS), Navrongo Senior High School (Navasco) and St John Bosco's College of Education (Bosco) were selected for the study. For Navasco, samples were taken from the kitchen wastewater while for UDS and Bosco the samples were taken from Navoro and Abedi Pele halls of residence respectively. Two samples, one from the point of discharge and the other at the point where the wastewater is collected, were taken from each institution. The sampling points were coded as follows: Bosco Sample 1 (BS1), Bosco Sample 2 (BS2), UDS Sample 1 (US1), UDS Sample 2 (US2), Navasco Sample 1 (NS1) and Navasco Sample 2 (NS2).

\subsection{Sampling Procedure}

Wastewater samples were collected in the month of May 2018 from the six sampling points. Using a Geographic Positioning System, locations of the sampling points were recorded and incorporated into the map of the study area. Discrete samples were collected into $1.5 \mathrm{~L}$ plastic bottles. The labelled sampling bottles were rinsed three times with the wastewater before filling them with the actual samples. All information pertinent to field survey and sampling was recorded in a bound log book. Samples were conveyed to the laboratory immediately after collection in an ice chest containing crushed ice in order to maintain a temperature of $4^{\circ} \mathrm{C}$ so as to prevent any changes to the chemical composition of the samples.

\subsection{Flowrate Determination}

Flow rate was determined on-site using the bucket and stopwatch method. A container of a known volume (4L) was placed under the pipe and all discharge flowed into the container. A stopwatch was used to record the time taken, in seconds, for the container to get full. The process was repeated four times to obtain an average flow rate.

\subsection{Laboratory Analysis}

BOD was measured by determining the dissolved oxygen (DO) concentration before and after incubation at $20^{\circ} \mathrm{C}$ for 5 days. The BOD is then calculated from the difference between the initial and final DO concentration.

Chemical Oxygen Demand was determined based on the closed tube reflux method. Briefly, $5 \mathrm{ml}$ of the sample was transferred into a labeled culture tube and $3 \mathrm{ml}$ potassium dichromate solution (digestion solution) added. $7 \mathrm{ml}$ of $\mathrm{H}_{2} \mathrm{SO}_{4}$ reagent (silver sulphate in sulphuric acid) was added carefully to form an acid layer under the sample-digestion layer. The tube was tightly corked, shaken and inverted several times to mix completely. The tubes were then parked in a digester at $150^{\circ} \mathrm{C}$ and reflux for two hours, and then cooled to room temperature. 1-2 drops of ferroin indicator was added and titrated with standard (FAS) solution until the color changes from bluegreen to reddish brown or wine at endpoint.

All other physicochemical parameters were determined based on standard methods (APHA, 1998) and the protocols of the laboratory of the Centre for Scientific and Industrial Research (CSIR), Tamale, Ghana.

\section{Results and Discussion}

\subsection{Flowrate}

Table 1 below contains the results of the flow rate measurements from the different sampling points.

Table 1. Table showing results of flow rate determination

\begin{tabular}{|l|l|l|}
\hline Institutions & Hourly discharge (L/h) & Total Discharge (L/d) \\
\hline Navasco & $68.08 / \mathrm{hr}$ & $408.48 / 6 \mathrm{hrs}$ \\
\hline UDS & $255.96 / \mathrm{hr}$ & $2047.68 / 8 \mathrm{hrs}$ \\
\hline Bosco & $374.01 / \mathrm{hr}$ & $1496.04 / 4 \mathrm{hrs}$ \\
\hline
\end{tabular}

The main source of wastewater from Navasco is the kitchen, which serves the entire student population for all the meals of the day. Activities such as washing of food stuff, utensils, tables and handwashing contributed to wastewater generated at the kitchen. At Bosco, the wastewater had its source mainly from the washrooms and so did not contain much food waste compared to Navasco. Activities such as bathing, washing, scrubbing contribute to the wastewater generated at the washroom. At UDS, the wastewater had its source from the washroom and the kitchen. This is because the students undertake cooking activities in their halls of residence, unlike in Navasco and Bosco where the students are fed from a dining hall. The wastewater flow from all these areas was not consistent since activities such as bathing and cooking were done mostly in the morning and evening. In particular, the afternoons recorded the lowest flowrates in all the sampling points as the students were generally out of their halls of residence.

\subsection{Physicochemical Parameters}

The levels of the measured physical and chemical parameters are contained in the Table 2 below. 
Table 2. Table showing levels of physicochemical parameters in wastewater samples

\begin{tabular}{|l|l|l|l|l|l|l|l|}
\hline PARAMETERS & BS1 & BS2 & US1 & US2 & NS1 & NS2 & $\begin{array}{l}\text { GHANA } \\
\text { GUIDELINE }\end{array}$ \\
\hline $\begin{array}{l}\text { Conductivity } \\
(\mu \mathrm{S} / \mathrm{cm})\end{array}$ & 993 & 1,679 & 1,960 & 1,742 & 791 & 2,949 & 1500 \\
\hline Nitrate (mg/l) & 0.053 & 0.071 & 0.763 & 0.166 & 0.048 & 0.166 & 75 \\
\hline Phosphorus (mg/l) & 30.77 & 10.31 & 23.38 & 9.318 & 0.482 & 79.78 & 2 \\
\hline Alkalinity (mg/l) & 1,000 & 1,600 & 1,800 & 1,400 & 1,000 & 1,400 & 1500 \\
\hline Chloride (mg/l) & 693 & 792 & 594 & 792 & 693 & 693 & 250 \\
\hline Hardness (mg/l) & 18,000 & 15,400 & 17,600 & 16,400 & 18,400 & 18,800 & 500 \\
\hline DO (mg/l) & 33.5 & 35.6 & 31.0 & 32.5 & 30.5 & 32.5 & \\
\hline BOD (mg/l) & 14.2 & 10.7 & 16.3 & 14.7 & 13.2 & 14.2 & 50 \\
\hline pH & 7.34 & 6.47 & 5.86 & 7.31 & 6.47 & 5.11 & $6-9$ \\
\hline
\end{tabular}

3.2.1 Conductivity

The conductivity measurements from the various sampling points were as follows: BS1 and BS2 had 993mg/l and $1679 \mathrm{mg} / 1$ respectively; US1 and US2 had $1640 \mathrm{mg} / 1$ and $1742 \mathrm{mg} / 1$ respectively; NS1 and NS2 had $791 \mathrm{mg} / 1$ and $2949 \mathrm{mg} / 1$ respectively. Figure 1 gives a graphical representation of these measurements, and the Ghana EPA guideline (indicated by the red line).

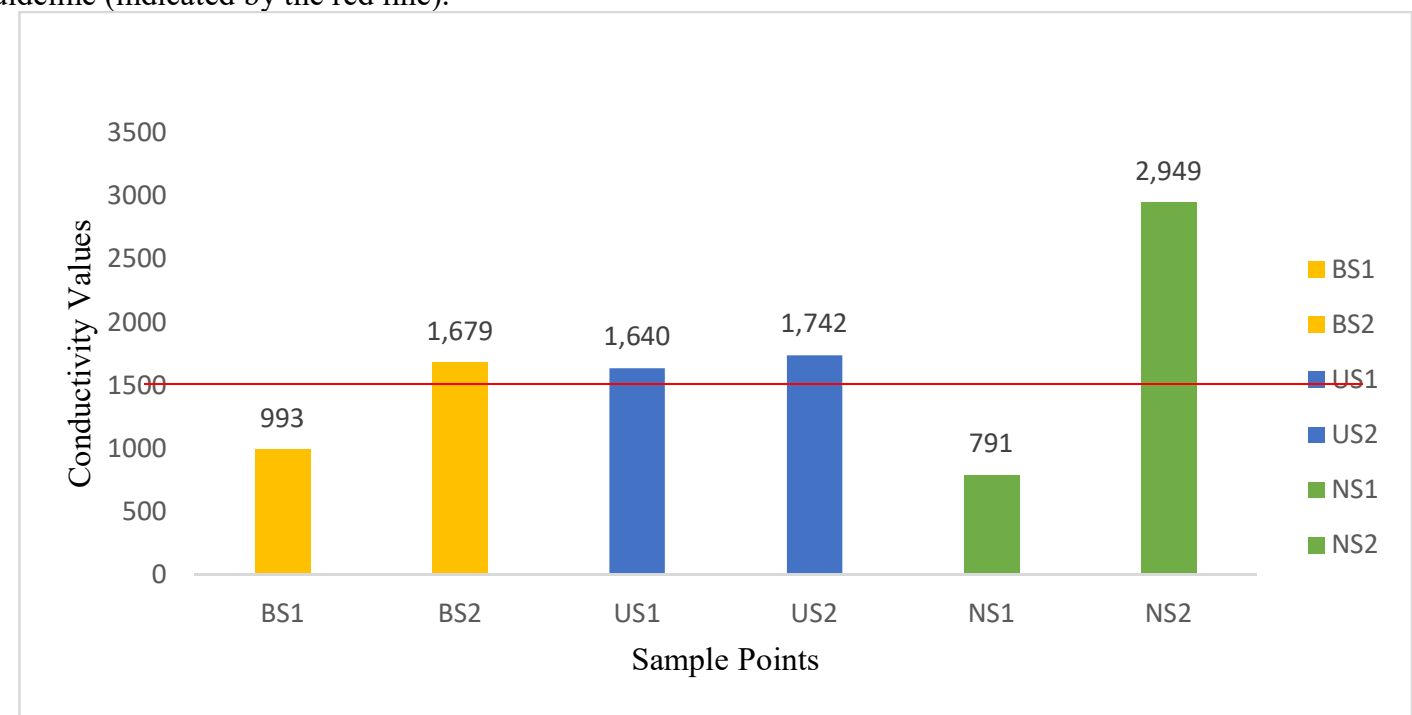

Fig 1: Figure Showing Conductivity Levels of Wastewater

Generally, conductivity of wastewater is measured to obtain the ability of the water to conduct electrical current. The values of conductivity generally exceed the Ghana EPA guideline value of 1500mg/l. The high conductivity levels may be attributed to high concentrations of dissolved ions present in the wastewater. A study revealed that effluent of conductivity $656.42 \pm 192.85$ was reduced by $48.3 \%$ after treatment using constructed wetlands (Muzola, 2007). In another study done by Kagya (2011) to determine effluent of two wastewater treatment system, waste stabilization pond reduced the conductivity of the influent by $49.34 \%$ whereas activated sludge recorded $25.18 \%$ removal. A natural method of treatment may be useful for reducing the levels of conductivity to standards acceptable by the EPA.

3.2.2 Alkalinity

The alkalinity of the wastewater samples ranged from $1000 \mathrm{mg} / 1$ at sampling point BS1 to $1800 \mathrm{mg} / 1$ at sampling point US1. Figure 2 below shows the values of alkalinity measured and the red horizontal line indicates the Ghana EPA guideline. 


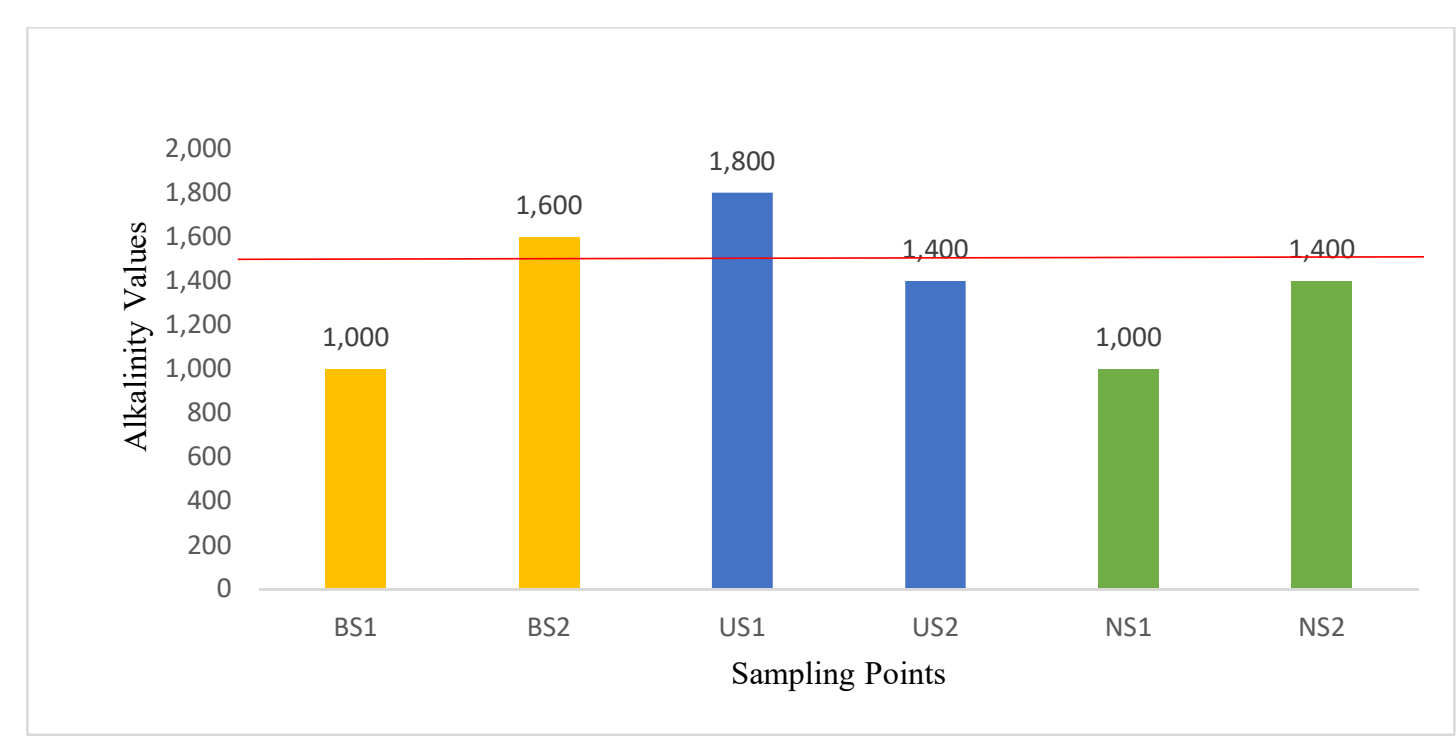

Figure 2. Figure Showing Alkalinity Levels

Alkalinity values were generally within the guideline value of $1500 \mathrm{mg} / \mathrm{l}$ set by the Ghana EPA, except for sampling points BS2 and US1 were the guideline value was exceeded. According to Jain (2000), higher values of alkalinity indicate the presence of bicarbonates, carbonates and hydroxide in wastewater. This may be due to the amount of suspended organic matter, salts of weak acids such as silicates and phosphates. Higher values of alkalinity are a threat to surface waters.

3.2.3 Phosphorus

The concentrations of phosphorus in the wastewater were consistently above the EPA effluent guideline value of $2 \mathrm{mg} / 1$. Samples BS1 and BS2 had $30.71 \mathrm{mg} / 1$ and $10.31 \mathrm{mg} / 1$ respectively. These values, when compared to the Ghana EPA effluent discharge guideline value, are unacceptable. US1 and US2 also had $23.38 \mathrm{mg} / 1$ and $9.32 \mathrm{mg} / 1$ respectively, and NS1 and NS2 had $0.48 \mathrm{mg} / 1$ and $79.78 \mathrm{mg} / 1$ respectively.

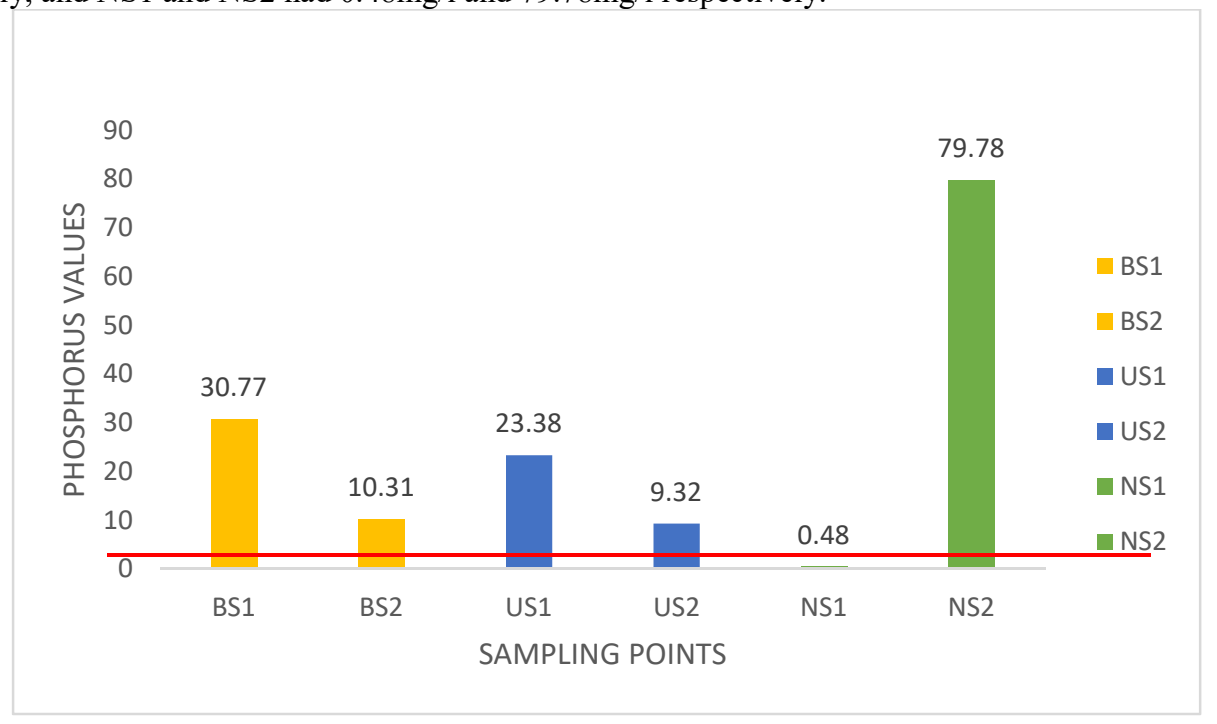

Fig 3. Figure Showing Phosphorus Concentrations of Wastewater.

Although phosphorus is an essential nutrient for plant growth and for biological metabolism, Tjandraatmadja et al (2010), argue that excessive discharge into aquatic environment can result in excessive algae growth, eutrophication and the depletion of oxygen in water bodies. According to Salvato et al (2003), phosphorus is usually associated with plant remains, animal wastes or fertilizer, but other potential sources of phosphates in wastewater as stated by Tjandraatmadja et al (2010), include cleaning products, cosmetic, medicated shampoos, food products, feaces and urine. All these sources, as observed at the various institutions have contributed greatly to the high levels of phosphate in the wastewater. A study on use of close-to-nature treatment methods revealed that an effluent phosphorus concentration of $12.43 \pm 4.46$ was reduced by $72 \%$ using constructed wetlands (Muzola, 
2007). Kagya (2011), in a similar research on the determination of effluent quality of two wastewater treatment system, indicated that waste stabilization ponds accomplished $92 \%$ removal of phosphorus.

3.2.4 Hardness

Levels of hardness for all the samples collected were above the Ghana EPA guideline value of $500 \mathrm{mg} / \mathrm{l}$, with the highest value of $18,800 \mathrm{mg} / 1$ recorded at sampling point NS2. Figure 4 below shows the hardness values and a red horizontal line indicating EPA guideline.

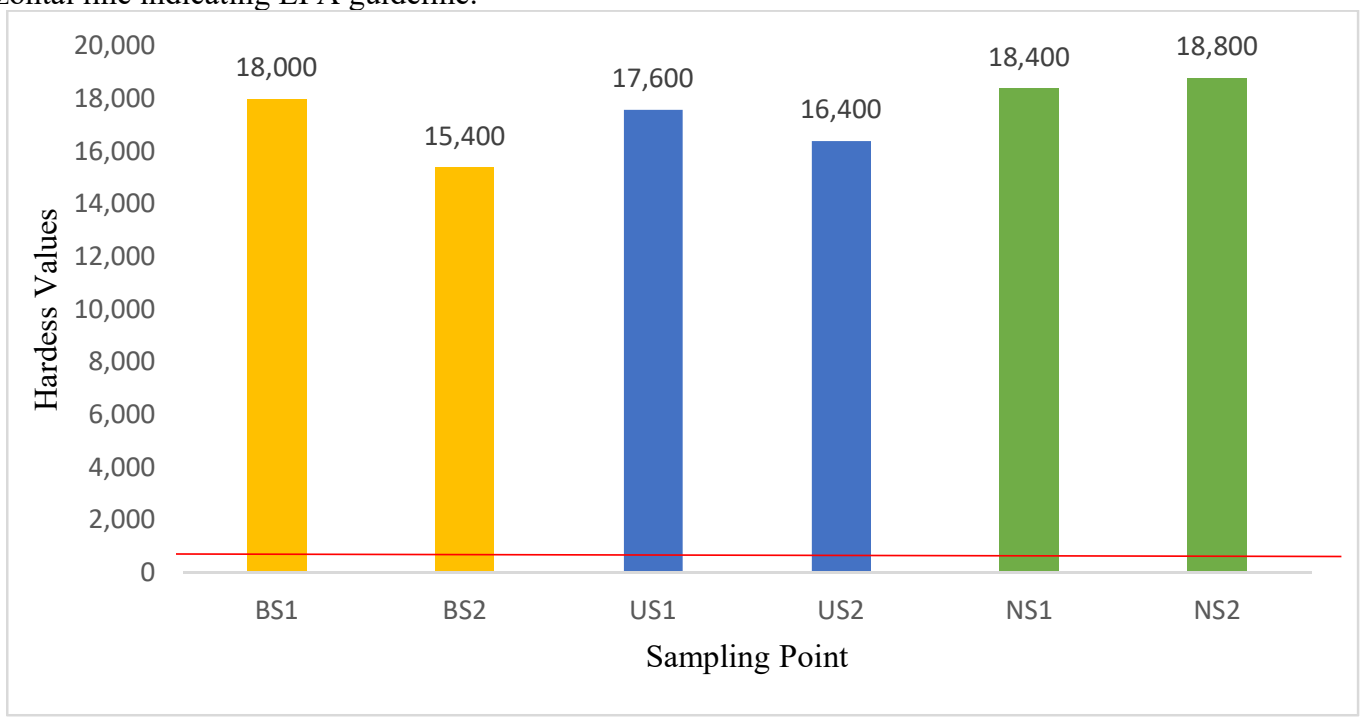

Figure 4. Figure Showing Hardness Levels of Wastewater.

Generally, hardness of wastewater is measured to obtain the concentration of Calcium $\left(\mathrm{Ca}^{2+}\right)$ and Magnesium $\left(\mathrm{Mg}^{2+}\right)$ ions. These institutions under study has their water source from groundwater. Also, since the source of the wastewater is domestic, soaps and salts cleaning might also contribute to the increased in values of the hardness WHO (2011). A study revealed that after a month of wastewater treatment using a natural treatment method, the concentration of hardness was reduced by $46.42 \%$ (Maharjan, 2017).

3.2.5 Chloride

Levels of chloride in all the samples were above the guideline value of $250 \mathrm{mg} / 1 \mathrm{set}$ by the EPA of Ghana. In particular, the sample points where the wastewater collects for Bosco and UDS recorded the highest concentrations of 792 and $793 \mathrm{mg} / \mathrm{l}$ respectively. Fig below gives a representation of these values; the red line indicates the guideline value.

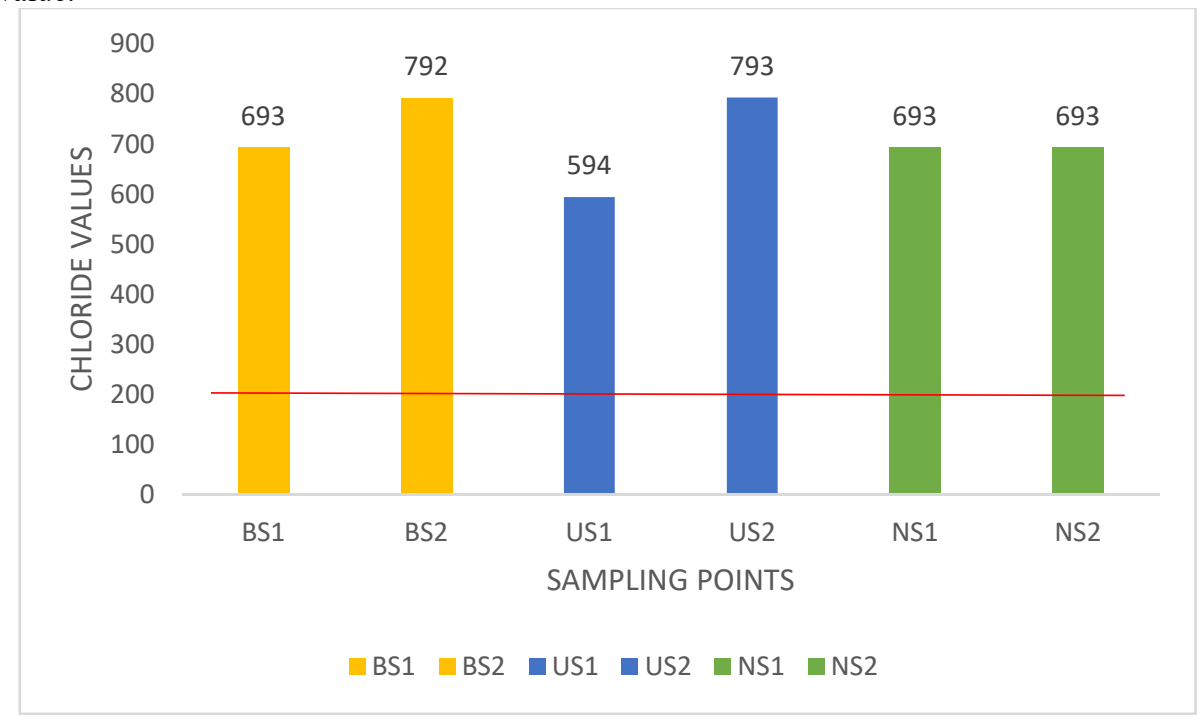

Fig 5. Figure Showing Chloride Concentration of Wastewater

Generally, the concentration of chloride in the wastewater should constitute a matter of concern considering the high levels. Chloride (Cl-) as an anion comes from the dissolution of natural salt deposits or contamination by 
activities of humans. It has been reported that high levels of chloride in water used for irrigation (30-100mg/l) can increase salinity in soil and cause decline in plant yield depending on the characteristics of the soil and the frequency the irrigation (ANZECC and ARMCANZ 2001). In the study area, the potential sources of chloride include medicated product, vegetables, processed food, personal care products and cosmetics. A study by Maharjan (2017) involving the use of phytoremediation to treat wastewater achieved a chloride reduction from 123.5 to 89 $\mathrm{mg} / \mathrm{l}$ within a month. This result holds promise for a situation as revealed by the current research.

\subsection{Proposal of a Suitable Treatment Method}

Wastewater treatment is essential for the maintenance of a healthy society and environment, and this is very evident especially in developing countries. However, the huge financial commitments associated with the provision of conventional treatment, coupled with the level of affordability by the people make the provision of such treatment methods very difficult. Therefore, there is the need for low-cost treatment methods to be adopted. The results from the characterization of the wastewater samples revealed the presence of the following contaminants; conductivity, $\mathrm{BOD}, \mathrm{N}, \mathrm{P}, \mathrm{Cl}, \mathrm{pH}$, hardness, alkalinity. Most of the samples had conductivity, alkalinity, hardness, phosphorus and chloride above the permissible limit for wastewater discharge according to EPA Ghana into the environment. From a general view, the quantity of the wastewater produced by these institutions require pre-treatment before discharge into the environment to limit pollution. The pollution level in the various contaminants in the wastewater was greater in Navoro Hall (UDS) followed by Abede Pele Hall (Boscos) and Navasco.

Selecting treatment options for these institutions requires considering factors such as efficiency, cost, maintenance and sustainability. For developing countries like Ghana and considering the volume and pollutants levels of wastewater it is recommended that constructed wetland be used for treatment because they are less expensive to construct, require less energy and low operation and maintenance cost. The municipality has vast land and temperature favourable for the operation of constructed wetlands. A research conducted on grey water treatment using wetlands system revealed that BOD, phosphorus, conductivity and nitrates levels were reduced by $88.4 \%, 72 \%, 48.3 \%$ and 41.9\% respectively (Muzola 2007). In a similar study by Asirvadam et al., (2017) on treatment of grey water using constructed wetland system, constituents such as hardness, BOD and conductivity in the grey water taken for treatment were successfully reduced by $32 \%, 67.27 \%$ and $66.59 \%$ respectively. Considering the levels of the investigated parameters in this study and the reduction levels reported by these authors, it is clear that the application of constructed wetlands will be a very cost effective method of providing some level of treatment before discharge into the environment.

\section{Conclusion}

In this study, physical and chemical parameters of wastewater from three institutions were analysed for the purpose of characterizing the wastewater so as to determine a suitable treatment method. In addition, flowrate measurements were made in order to calculate the quantity of wastewater generated daily from the various institutions. It was revealed that levels of hardness, alkalinity, phosphorus and chlorides were above their respective guideline values recommended by the EPA of Ghana. The levels were highest when kitchen wastewater is combined with wastewater from washrooms. Undoubtedly, the continuous discharge of this untreated wastewater into the environment poses serious environmental problems especially with regards surface water quality. These findings are useful for the municipal authorities in determining which method of treatment will be suitable and appropriate. Also, the regulatory agency should ensure that these institutions perform some level of treatment before discharge. It is recommended that constructed wetlands should be explored as a way forward considering the strength and quality of the wastewater. In this respect, research needs to be conducted to identify a suitable plant for use as the weed bed taking in account the wastewater composition as well as the environmental conditions pertaining to this ecological zone.

\section{REFERENCES}

Amoah, I. D., Abubakari, A., Stenstron, T. A., Abaidoo, R. C., Seidu, R. 2016, Contribution of wastewater Irrigation to soil transmitted Helminths infection among vegetable farmers in Kumasi, Ghana. doi:10.1371/journal.pntd.005161.

Amuzu. A. T. (1997). The Impact of Urbanisation and development on surface waters in Ghana.

ANZECC and ARMCANZ (2001) Australian and New Zealand Guidelines for Fresh and Marine Water Quality, Chapter 4, Primary Industries, Australian and New Zealand

Environment and Conservation Council and Agriculture Resource Management Council of Australia and New Zealand.

APHA, AWWA, WEF (1998) standards and methods for Examination of Water and Wastewater, 20 ${ }^{\text {th }}$ Edition, Washington DC.pp.5-2 to 5-6.

APHA, AWWA, WEF (1995). Standard Methods for the Examination of Water and Wastewater. 19 THedition, pp 2.1-2.3, 2-56 
Asirvadam, D. P., Bharathi, K. D., Durairaj, P., Kaleeswaran, M., \& Abinaya, S. (2017). “Treatment Of Grey Water Using Constructed Wetland System", International Journal of Engineering Research and Modern Education, Special Issue, April, Page Number 116-118.

Awuah, E., Richard, A. K., Samuel, F.G., Henk, J. L. and Huub, J. G. (2014). Characterization and Management of Domestic Wastewater in Two Suburbs of Kumasi, Ghana. Research Journal of Environmental Sciences, $8: 318-330$.

Boadi, K. O. and Kuitunen, M. 2002. Urban waste pollution in the Korle Lagoon, Accra, Ghana. Department of Biological and Environmental Sciences, Faculty of Mathematics and Science, University of Jyvaskyla, Finland.

Bos, R., Ziegelbauer, K., Speich, B., Mausezah, D., Keiser, J., et al. (2012). Effects of sanitation on soil transmitted Helminth Infection: Systematic review and Meta-Analysis. PLoS Med 9(1): e1001162. Doi: 10.1371/journal.pmed.100116

Environmental Protection Agency, Ghana (1997), Specific Effluent Quality Guidelines for Discharge into Natural Waterbodies (Maximum Permissible Levels).

Ghana statistical Service, P. and H. C. (2014). Kassena nankana east municipality.

Ghana Statistical Service. 2014 Population and Housing Census. www.statsghana.gov.gh

Graham, J. P. and Polizzotto. (2013). Pit latrines and their impacts on groundwater quality: a systematic review. Environmental Health Respect.

Jain, C. 2000. Groundwater quality in sugar districts Madhya Pradesh, India. Jr.Env.Health, 42(4):151-158. 2000.

Jiménez, B. and Asano, T. 2008. 'Water reclamation and reuse around the world', Water Reuse: An International Survey of Current Practice, Issues and Needs,IWA Publishing, London, p648.

Kagya, A. W. (2011). Determination of effluent quality of two wastewater treatment systems: an Activated Sludge treatment plant and waste stabilization ponds at Juapong. MSc thesis.

Keriata, B., Drechsel, P. (2002). International water management institute (IWMI). Wastewater use in informal irrigation in urban and peri-urban areas of Kumasi.

Maharjan, A., Pradhanang, S. 2017. Potential of Vetiver Grass for Wastewater Treatment. Central Department of Environmental Science, Tribhuvan University, Nepal. Environment and Ecology Research 5(7): 489-494.

Mara, D. (2004). Domestic wastewater treatment in developing countries. First published by Earthscan in the UK and USA in 2004.

Michael, R. T., Butler, D. (2011). Introduction to wastewater treatment. Page (8).

Muzola, A. (2007). Grey water treatment using natural wetlands. KNUST MSc thesis.

Natural resource Ministries, Australian Health Ministers Conference,Environmental Protection and Heritage Council report.(NRM/AHMC/EPHC, 2006).

Nikiema, J., Figoli, N., Langergraber, G., Marrot and Moulin, P. (2013). Wastewater Treatment Practices in Africa: Experiences from countries. Sustainable Practices issues 14/2013, pp: 26-34.

Norah, M., Shumirai, Z., Zelma, M. L. and Upenyu, M. 2015. Impacts of Untreated Sewage Discharge on Water Quality of Middle Manyame River: A Case of Chinhoyi Town, Zimbabwe. International Journal of Environmental Monitoring and Analysis. Vol. 3, No. 3, 2015, pp. 133-138. doi: 10.11648/j.ijema.20150303.14

Prüss-Üstün, A., Corvalán, C. 2006. Preventing disease through healthy environments: World Health Organization Geneva; 2006.

Rousseau, D. and Sharma, S. (2011). Natural Systems for wastewater Treatment and Reuse. UNESCO-IHE,DelFt, The Netherlands 24-26. January, Paris Conference.

Salvato, J. A., Nemerow, N. and Agardy, F. (2003). "Environmental Engineering", John Wiley and Sons, Inc. New Jersey, USA.

Sperling, V. M. (2007). Biological wastewater treatment series. Vol 1, Wastewater characteristics, Treatment and Disposal, Published by IWA Publishing, Alliance House, 12 Caxtoon Street, London SW1H OQS, UK.

Stikker, A. (1998). Water Today and Tomorrow, Prospects for Overcoming Scarcity, Futures, Vol. 30, No. 1 Elsevier Science Ltd., Great Britain.

Stendahl, K. (1990). "Handbook on Water Treatment", Kemira Kemi AB, Helsingborg, Sweden.

Taylor, K. E., Caza, N., Bewtra, J. K. and Biswas, N. (1999). Removal of phenolic compounds from synthetic wastewater using soyabean peroxidase. Water research, 30(4), 954-964.

Tjandraatmadja, G., Pollard, C., Sheedy, C. and Gozukara, Y. (2010), "Sources of Contaminants in Domestic Wastewater: Nutrients and Additional Elements from Household Products. CSIRO: Water for a Healthy Country National Research Flagship, Australia.

UNICEF, (2016). Assessment of wastewater treatment plants in Ghana, By Civil Engineering Department KNUST, July.

UN. ESCWA,(2003). Wastewater treatment technologies: A General Review.

U.S.EPA, 1998, Total Suspended Solids Laboratory Method 160.2, cited August 2002: 
http://www.epa.gov/region09/lab/sop

Walker, C. L. F., Rudan, I., Liu, L., Nair, H., Theodoratou, E., Bhutta, Z. A., et al. 2013. Global burden of childhood pneumonia and diarrhoea. The Lancet. 2013; 381(9875):1405-16.

WHO, (2011). Guidelines for drinking water quality.

WWAP (United Nations World Water Assessment Programme). 2017. The United Nations World 